\title{
The Moral Superiority Effect: Self Versus Other Differences in Satisfaction With Being Overpaid
}

\author{
Susanne L. Peters, ${ }^{1,3}$ Kees van den Bos, ${ }^{1}$ and D. Ramona Bobocel ${ }^{2}$
}

This paper focuses on how people think about their own and other's reactions to being overpaid. Two experiments investigate the discrepancy between people's own satisfaction and their perception of other's satisfaction with overpayment. The results of both experiments support our hypothesis that people think others are more satisfied with being overpaid than they are themselves. Our results are consistent with the idea that people think others are more influenced by egoism-based considerations whereas they themselves are more influenced by considerations of right and wrong. In other words, people show a moral superiority effect. In the general discussion, we argue why it is less likely to find moral superiority effects on people's reactions to being equally paid and underpaid, and we relate our findings to the literature of self-serving biases.

KEY WORDS: fairness; self-interest; overpayment; satisfaction.

People frequently encounter situations in which they must evaluate the outcomes that they have received. Ideally, in making these evaluations, people's interests coincide with the fairness of the situation. On many occasions, however, people may find themselves in a mixed-motive situation in which their own interests conflict with fairness. How do people evaluate their outcomes in such situations?

Numerous scientific disciplines, including psychology, economics, sociology, and political sciences, have focused on the intriguing relationship between selfinterest and fairness (for overviews, see, e.g., Beauchamp, 2001; Cohen, 1986). The current paper examines this issue from a social psychological perspective.

\footnotetext{
${ }^{1}$ Department of Social and Organizational Psychology, Utrecht University, Utrecht, The Netherlands. ${ }^{2}$ Department of Psychology, University of Waterloo, Canada.

${ }^{3}$ All correspondence should be addressed to Susanne Peters, Department of Social and Organizational Psychology, Utrecht University, Heidelberglaan 1, 3584 CS Utrecht, The Netherlands; e-mail: s.peters@fss.uu.nl.
} 
More specifically, this paper focuses on the conflict between egoism-based pleasure and fairness considerations that arise in situations of overpayment inequity (Adams, 1965). Therefore, this paper focuses on two important topics: How people react to being advantaged (e.g., see Montada et al., 1986), and how people experience pleasure and satisfaction (see Kahneman et al., 1999). We suggest that, when confronted with overpayment, people think their own reaction is more moral than the reaction of others; in other words, we propose a moral superiority effect. In the following sections, we review the relevant literatures that served as the basis for our predictions.

\section{FAIRNESS AND SELF-INTEREST}

In their 1983 paper, Messick and Sentis argue that one's behavior toward others is often characterized by a conflict between what one wants and what one believes to be right. These two motives are distinct but both play an important role in people's evaluation with outcomes. Fairness considerations ${ }^{4}$ are moral beliefs and rules about right and wrong and about what should and what should not be done. People want, according to Haidt (2000), to be moral, to do the right thing, and to be seen as ethical. Haidt (2000) argues that moral motives are even spoken of as the highest and noblest motives that people can have. Yet, at the same time, people want to live a nice life, and for this and other hedonistic reasons, they pursue their self-interest ${ }^{5}$ (Hobbes, 1651/1904). On the basis of research on judgment and choice (e.g., Boles and Messick, 1995; Loewenstein et al., 1989; Messick and Sentis, 1985), we argue that people wish to do the right thing and at the same time to maximize their outcomes.

Situations exist in which there is no conflict between fairness and self-interest motives. For example, when two people work equally hard and get paid equally for their effort, there is no conflict between fairness and self-interest; both motives evoke positive reactions. In addition, when two people work equally hard but one of them gets paid less for his or her effort, there is again no conflict between fairness and self-interest for the disadvantaged person; neither self-interest nor fairness is served from the perspective of the disadvantaged person, and this person will have consistently negative reactions. However, when two people work equally hard but one of them gets paid more, there is a conflict between fairness and self-interest for the advantaged person. On the one hand, it is nice to receive a relatively good outcome, but on the other hand it is not fair to receive a better outcome than a comparable other person. People who are being overpaid are in conflict between what they want and what they believe to be right, and this creates tension (Adams,

\footnotetext{
${ }^{4}$ In the present paper, the term fairness includes related concepts such as justice and morality.

${ }^{5}$ In the present paper, the term self-interest includes related concepts such as egoism, hedonism, and self-centeredness.
} 
1965). Both motives can influence people in different amounts and therefore there is more leeway in people's reactions to situations of overpayment inequity. It is fascinating to see how people deal with this conflict between self-interest and fairness and it is captivating to see how people react to being overpaid.

\section{HOW DO PEOPLE EVALUATE OVERPAYMENT?}

Earlier equity studies have examined people's reactions to equity, overpayment (or advantageous) inequity, and underpayment (or disadvantageous) inequity. Following earlier equity studies (e.g., Austin et al., 1980; Van den Bos et al., 1997, 1998), this paper studies people's reactions to being overpaid by exposing participants to situations in which there is another person who is comparable to participants with respect to the amount of input they have provided. The outcome that participants receive is held constant across conditions. To compose arrangements of overpayment, participants are informed that their own outcome is better than the outcome of the other participant. The most widely studied dependent variable in equity studies is people's satisfaction with equitable or inequitable arrangements (e.g., Adams, 1965); therefore, people's satisfaction with arrangements of overpayment is measured in the present research.

On the basis of equity theory (e.g., Adams, 1965; Austin et al., 1980; Austin and Walster, 1974; Buunk and Van Yperen, 1989; Van den Bos et al., 1997), it can be argued that, when forming judgments of outcome satisfaction, individuals who are faced with inequity will feel distress and will be less satisfied than individuals who are faced with equity. As noted by Adams (1965): "There can be little doubt that inequity results in dissatisfaction" (p. 283). Furthermore, it can be argued that people who are confronted with being overpaid have to deal with conflicting social motives when forming judgments of outcome satisfaction. When people are confronted with overpayment there is a conflict between what one wants and what one believes to be right (Messick and Sentis, 1983). Following earlier equity studies (e.g., Adams, 1965), we propose here that when people are overpaid, there is one source of negative affect and one source of positive affect: The negative source is the fairness-based feeling of guilt of being unjustly advantaged (e.g., Montada, 2002; Montada et al., 1986), whereas the positive source is the egoismbased pleasure of receiving a relatively good outcome (cf. Van den Bos et al., 1997, 1998).

In other words, following Messick and Sentis' (1983) reasoning, when reacting to being overpaid, it can be argued that there is a conflict between one's preferences (high outcomes; cf. Loewenstein et al., 1989) and what one believes to be right (equal outcomes; cf. Messick, 1993), and this conflict pulls people in two opposite directions. Therefore, the prediction that is usually made in equity studies is that one source of positive emotional experience (egoism-based pleasure) and one source of negative emotional experience (guilt from being unjustly 
advantaged) will lead to moderate satisfaction with an outcome. That is, people are usually less satisfied with being overpaid than with being equitably paid, but more satisfied with being overpaid than with being underpaid. This pattern of findings is precisely what is typically found in equity studies (e.g., Buunk and Van Yperen, 1989; Van den Bos et al., 1997, 1998). On the basis of these findings, then, we expect that people will usually be moderately satisfied with arrangements of overpayment.

The current paper proposes a moral superiority effect. On the basis of research literature on the conflict between fairness and self-interest (Messick and Sentis, 1983) and on self-serving biases (Epley and Dunning, 2000; Nisbett and Ross, 1980; Smith and Mackie, 1990), we argue that people believe that they react differently than others to being overpaid. More specifically, we suggest that people think that their own reaction is more moral than the reactions of others when confronted with overpayment. Below, we explain the derivation of this prediction.

\section{THE MORAL SUPERIORITY EFFECT IN SITUATIONS OF OVERPAYMENT INEQUITY}

When asking the question of how people think others will react to overpayment inequity, it is important to note that previous research in social psychology has revealed some tendencies for people to rate themselves as superior to others in a number of domains (for reviews, see, e.g., Epley and Dunning, 2000; Nisbett and Ross, 1980; Smith and Mackie, 1990). For example, Epley and Dunning (2000) found that people think that they contribute more to public goods than others do. This and other findings suggest that especially in a situation where there is more leeway for people's reactions, such as in an overpayment situation, there is a possibility that self-serving biases will be evident. That is, people may think that others will react more positively toward overpayment than they themselves would. Interestingly, this idea has, to our knowledge, never been tested empirically.

In related research, Messick and associates found that people tend to see their acts as producing predominantly fair outcomes and the acts of others producing relatively more unfair outcomes (Messick and Sentis, 1983; Moore and Baron, 1973). Also, Mischel et al. (1976) showed a memory bias such that recall was better for feedback about one's good traits than feedback about one's faults and shortcomings. Furthermore, Jencks (1990) said: "Virtually all of us assume that when interests conflict, most of our neighbors will habitually place their own interest ahead of other people's" (p. 56).

The findings of Messick et al. (1985) are particularly relevant to the present research. These authors found a tendency for people to associate other persons with unfair behaviors. That is, participants could think of more unfair behaviors of others and more fair behaviors of themselves relative to fair behaviors of others 
and unfair behaviors of themselves. Messick et al. (1985) concluded that people think others do unfair things more often than they do themselves and that others do fair things less often than they do themselves. These findings have been replicated by Liebrand et al. (1986).

As noted by Cates and Messick (1996), however, Messick et al. (1985) assessed only frequency ratings of fair and unfair behaviors. As social psychologists, we are interested not only in the frequency with which people associate certain behaviors with themselves and others, but also-and perhaps to a greater extent-in people's reactions to equitable and inequitable arrangements for themselves and others (cf. Adams, 1965). In fact, none of the previous studies cited above have examined self-serving biases in situations of overpayment inequity. Therefore, to date, we do not know whether these effects can be found on ratings commonly measured in equity studies.

In addition to this methodological limitation, there is a conceptual reason why we chose to examine this question. As noted earlier, arrangements of overpayment are characterized by a conflict between self-interest and fairness considerations. This conflict implies that people's satisfaction judgments are typically influenced by both self-interest and fairness components, which makes these judgments susceptible to both these dimensions of human reactions. Past research, such as Messick et al. (1985), measured only frequency ratings of fair and unfair behaviors and hence focused only on one dimension (more vs. less fairness) instead of two dimensions (fairness and self-interest). In the present research, we examine the full, two-dimensional account of the conflict between self-interest and fairness, and we will do this by focusing on arrangements of overpayment.

Another highly relevant line of work is research by Miller (1999) and Miller and Ratner (1998). These authors examined the real and the assumed power of self-interest. Participants in their studies thought others were more led by their self-interest in situations that mattered to them than was really the case. Although Miller and Ratner (1998) measured more general tendencies of the influence of self-interest, their findings inform our more specific hypothesis about the influence of the self-interest component.

As mentioned earlier, we focus on arrangements of overpayment, to allow us to examine the conflict between self-interest and fairness. The influence of self-serving biases has not yet been investigated in the context of overpayment, and we think it is especially interesting to do so because of the conflict between two motives that is present in such situations.

In summary, on the basis of the literature described above, we suggest that arrangements of overpayment are characterized by a conflict between egoismbased considerations and fairness considerations (e.g., Adams, 1965), and we expect a discrepancy between one's own satisfaction and one's judgment of others' satisfaction with these arrangements (e.g., Messick et al., 1985). Thus, we predict 
that people will be moderately satisfied with being overpaid and will think that others are more satisfied with being overpaid than they themselves are. In other words, we expect a moral superiority effect in satisfaction with overpayment.

We tested the presence of this moral superiority effect in two experiments. In addition to arrangements of overpayment, two conditions in which people were equitably paid or underpaid were included. These arrangements are commonly included in equity studies (Austin et al., 1980; Van den Bos et al., 1997, 1998) and were included here for exploratory purposes.

\section{EXPERIMENT 1}

Experiment 1 was constructed following the experimental paradigm developed by Van den Bos et al. (1997, Experiment 2). Participants completed tasks together with another participant and learned that their own task performance was comparable to the other participant's task performance. The outcome that participants received for their performance was either better than the outcome received by the other participant, worse than the outcome of the other participant, or equal to the outcome of the other participant. The outcome that participants received was held constant, while the outcome of the other participant was varied. Outcome satisfaction was the main dependent variable. Half of the participants were asked how satisfied they were with their outcome. The other half of the participants was asked how satisfied they thought the other participant would be with their outcome.

\section{Method}

\section{Participants and Design}

One hundred and twenty students (50 men and 70 women) at the Free University Amsterdam participated in the experiment and were paid for their participation. Participants were randomly assigned to one of the conditions of the 2 (target of rating: self vs. other) $\times 3$ (target's payment: equal payment vs. overpayment vs. underpayment) between-subjects factorial design.

\section{Experimental Procedure}

Participants were invited to participate in a study on how people perform tasks. In the first part of the instructions, participants were informed that they would be participating in the experiment with another person. The experimental procedure was then outlined to the participants: After the experimental tasks were explained, participants would practice the tasks for $2 \mathrm{~min}$, after which time they 
would work on the tasks for $10 \mathrm{~min}$. Furthermore, participants were informed that, after everyone had participated, a lottery would be held. The winner of this lottery would receive 100 Dutch guilders. (Actually, after all participants had completed the experiment, the 100 Dutch guilders were randomly given to a participant; a procedure to which none of the participants objected.) Participants were told that a total of 200 lottery tickets would be divided among all participants. Furthermore, participants were told that after the work round the experimenter would divide some lottery tickets between them and the other participant.

The tasks were then explained to the participants. Participants were asked to count the number of squares in a figure that showed a certain pattern. The practice round then began, after which the work round began. After the work round had ended, participants were told how many tasks they had completed in the work round (i.e., the number of figures that the participant had counted), and it was communicated to the participant that the other participant had completed an equivalent number of tasks. At this moment, participants were asked three questions that measured the comparability of the other participant. To assess whether participants thought of the other participant as a target of social comparison, they were asked to what extent the other participant worked equally hard in reference to the participants themselves $(1=$ much worse, $4=$ equally hard, $7=$ much better), to what extent the other participant did his or her best in reference to the participants themselves $(1=$ much worse, $4=$ equally, $7=$ much better $)$, and to what extent the other participant was good at performing the tasks in reference to the participants themselves $(1=$ much worse, $4=$ equally good, $7=$ much better).

Participants were then informed that the experimenter would divide the lottery tickets between them and the other participant. It was communicated to the participants that they received three lottery tickets. This was followed by the manipulation of the outcome of the other participant. In the overpayment condition, participants were informed that the other participant received one ticket. In the equal payment condition, participants were informed that the other participant received three tickets. In the underpayment condition, participants were informed that the other participant received five tickets.

Participants were then asked questions that served as our dependent variables and manipulation checks. All ratings were made on 7-point scales and were measured anonymously. Participants in the other-target conditions responded to the dependent variables from the viewpoint of the other participant. These participants had to judge whether they thought the other participant was, for example, satisfied with his or her outcome. Participants in the self-target conditions responded to the dependent variables from their own viewpoint. These participants had to judge whether they thought they were, for example, satisfied with their own outcome.

Main dependent variables were satisfaction judgments. Participants were asked to rate target's satisfaction with the outcome. They were asked how satisfied 
the target was with the lottery tickets that the target received $(1=$ very dissatisfied, $7=$ very satisfied $)$ and how pleasant the target judged the lottery tickets that the target received $(1=$ very unpleasant, $7=$ very pleasant $)$. Participants' answers on these ratings were averaged to form a scale of satisfaction with outcome $(\alpha=0.81)$.

As a manipulation check of outcome, fairness judgments were solicited by asking questions about the fairness of the lottery tickets received. Participants were asked how fair the target judged the lottery tickets that the target received $(1=$ very unfair, $7=$ very fair $)$ and how just the target judged the lottery tickets that the target received $(1=$ very unjust, $7=$ very just $)$. These items were averaged to form a reliable scale of fairness judgments $(\alpha=0.97)$.

\section{Results}

\section{Additional Measures}

Participants' ratings of the other participant as a comparable person were subjected to a $2 \times 3$ MANOVA. This MANOVA did not yield significant results at either the multivariate or univariate levels. Inspection of the means indicated that participants thought that the other participant worked equally hard $(M=4.0)$, had equally done his or her best $(M=3.9)$, and was equally good in performing the task $(M=4.0)$.

\section{Fairness Judgments}

Participants' outcome fairness judgments yielded only a main effect of outcome, $F(2,114)=49.91, p<0.01$. As expected, a least significant difference test $(p<0.05)$, revealed that participants in the equal payment condition judged their outcome to be more fair $(M=5.5, \mathrm{SD}=1.0)$ than those in the overpayment $(M=3.8, \mathrm{SD}=1.4)$ and underpayment conditions $(M=2.6, \mathrm{SD}=1.3)$; the difference between the latter conditions was not significant. These findings are in accordance with previous equity studies (e.g., Van den Bos et al., 1997, 1998), which show that equitable outcomes are judged to be fair and inequitable outcomes to be unfair, hence providing additional evidence that the manipulation of outcome was perceived as intended.

\section{Perceived Satisfaction}

Main dependent variables were participants' perceptions of outcome satisfaction. To analyze the data, we first conducted a $2 \times 3$ analysis of variance (ANOVA) on these ratings. The ANOVA showed a significant main effect of target of rating, $F(1,114)=4.02, p<0.05$, a significant main effect 
Table I. Means and Standard Deviations of Outcome Satisfaction of Self and Other as a Function of Target's Payment (Experiment 1)

\begin{tabular}{|c|c|c|c|c|c|c|}
\hline & \multicolumn{6}{|c|}{ Target's payment } \\
\hline & \multicolumn{2}{|c|}{ Equal payment } & \multicolumn{2}{|c|}{ Overpayment } & \multicolumn{2}{|c|}{ Underpayment } \\
\hline & $M$ & $\mathrm{SD}$ & $M$ & $\mathrm{SD}$ & $M$ & SD \\
\hline Self & $5.2_{\mathrm{b}}$ & 0.9 & $5.0_{\mathrm{b}}$ & 1.4 & $3.7_{\mathrm{c}}$ & 1.6 \\
\hline Other & $5.4_{b}$ & 0.7 & $6.1_{\mathrm{a}}$ & 0.6 & $3.7_{\mathrm{c}}$ & 1.1 \\
\hline
\end{tabular}

Note. Means are on 7-point scales, with higher values indicating higher levels of outcome satisfaction. Means with no subscripts in common differ significantly ( $p<0.05$ ), as indicated by a least significant difference test for multiple comparisons between means (Kirk, 1982).

of outcome, $F(2,114)=33.27, p<0.01$, and a significant interaction effect, $F(2,114)=3.19, p<0.05$. To interpret these effects, we performed a least significant difference test for multiple comparisons between means $(p<0.05$; Kirk, 1982). Table I shows the results of this test. As hypothesized, findings revealed that, within the overpayment condition, participants judged the other participant's satisfaction as higher than their own satisfaction. Thus, participants thought that others were significantly more satisfied with being overpaid than they reported themselves to be. There were no effects of target of rating within the equal payment and underpayment conditions.

Additionally, it can be noted that there was a tendency within the self-target conditions for outcome satisfaction to be somewhat higher in the equal payment condition than in the overpayment condition. This pattern was reversed in the other-target conditions. Here, outcome satisfaction was higher in the overpayment condition than in the equal payment condition. Thus, the results of this study suggest that people think that other people will be more satisfied when they are inequitably advantaged compared to when they are equally paid, whereas this does not apply to oneself.

\section{Discussion}

Our hypothesis that people think that others are more satisfied with being overpaid than they are themselves is supported in Experiment 1. As our results show, participants evaluated the satisfaction of the other participant to be higher than their own satisfaction. In other words, people showed a moral superiority effect.

We did not completely replicate the findings of previous equity studies. Usually, it is found that people are more satisfied with equitable arrangements than with advantageous inequitable arrangements. However, this difference was not statistically significant in Experiment 1 (see the upper row of Table I). Before 
strong conclusions are drawn, we deemed it necessary to conduct a second experiment. The two main goals of Experiment 2 were to replicate the moral superiority effect and to replicate the findings of previous equity studies in the self-target conditions. Another important goal of Experiment 2 was to make the measures more solid methodologically, as explained below.

\section{EXPERIMENT 2}

It could be argued that when participants are in an experimental situation, such as in Experiment 1, they are experiencing their own situation but they have to imagine the situation of the other person. Therefore, in Experiment 2, participants responded to a manipulation of outcome that was induced by means of scenarios. When responding to the scenario, participants were asked to imagine both themselves and a comparable other person to be in a particular situation. Thus, the scenario methodology enabled us to make participants' reactions in the self- and other-target conditions more comparable, which has a methodological advantage. The scenarios used in Experiment 2 were constructed following earlier research by Van den Bos (1999, Experiment 1). The outcome that participants received in the scenario was held constant across conditions, and we varied whether the outcome was equal to the outcome of a comparable other person in the scenario (equal payment condition), better than the outcome of the other person (overpayment condition), or worse than the other person's outcome (underpayment condition). Outcome satisfaction was the main dependent variable. Half of the participants rated their own outcome satisfaction; the other half of the participants rated the other person's outcome satisfaction.

\section{Method}

\section{Participants and Design}

One hundred and twenty-two students (51 men and 71 women) at the Free University Amsterdam participated in the experiment and were paid for their participation. Participants were randomly assigned to one of the conditions of the 2 (target of rating: self vs. other) $\times 3$ (target's payment: equal payment vs. overpayment vs. underpayment) between-subjects factorial design.

\section{Experimental Procedure}

Participants read the scenario and answered the questions that constituted the dependent variables. On arrival at the laboratory, participants were led to separate cubicles, each of which contained a computer with a monitor and a keyboard. 
The computers were used to present the stimulus information and to measure the dependent variables.

First, participants were asked to imagine the following situation:

Last summer you had a job together with a fellow student. The two of you worked together in a pair. There were a large number of such pairs in the organization where you worked. You and your fellow student have worked equally hard and performed equally well. Because the organization has performed well last summer, it is announced on the last day of summer that a bonus of 10,000 Dutch guilders will be distributed among all employees. A certain amount of money has been allocated to you and your fellow student. It has to be decided how this amount of money will be distributed between you and your fellow student.

This was followed by the manipulation of outcome. Participants read the following sentences (manipulated information in italics):

A week after this, employees are paid. You receive a bonus of 500 Dutch guilders. Your fellow student receives a bonus of 250/500/750 Dutch guilders.

After participants had read the scenario, they were asked questions constituting the dependent variables. All ratings were made on 7-point scales and were measured anonymously. Main dependent variables were satisfaction judgments. Participants were asked how satisfied the target was with the bonus that the target received $(1=$ very dissatisfied, $7=$ very satisfied $)$ and how pleasant the target judged the bonus that the target received $(1=$ very unpleasant, $7=$ very pleasant $)$. The satisfaction ratings were averaged to form a scale of satisfaction with outcome $(\alpha=0.66)$.

As in Experiment 1, fairness judgments were included as a manipulation check of outcome by asking participants how fair the target judged the bonus that the target received $(1=$ very unfair, $7=$ very fair $)$ and how just the target judged the bonus that the target received $(1=$ very unjust, $7=$ very just $)$. These items were averaged to form a scale of fairness judgments $(\alpha=0.96)$.

\section{Results}

\section{Fairness Judgments}

Participants' outcome fairness judgments yielded only a main effect of outcome, $F(2,117)=143.05, p<0.01$. As expected, a least significant difference test $(p<0.05)$, revealed that participants in the equal payment condition judged their outcome to be more fair $(M=6.2, \mathrm{SD}=0.7)$ than those in the overpayment $(M=2.7, \mathrm{SD}=1.6)$ and underpayment conditions $(M=2.1, \mathrm{SD}=1.0)$; the latter difference between conditions was not significant. These findings are in accordance with Experiment 1 and previous equity studies (e.g., Van den Bos et al., 1997, 1998) and yield evidence that the manipulation of outcome was perceived as intended. 
Table II. Means and Standard Deviations of Outcome Satisfaction of Self and Other as a Function of Target's Payment (Experiment 2)

\begin{tabular}{|c|c|c|c|c|c|c|}
\hline & \multicolumn{6}{|c|}{ Target's payment } \\
\hline & \multicolumn{2}{|c|}{ Equal payment } & \multicolumn{2}{|c|}{ Overpayment } & \multicolumn{2}{|c|}{ Underpayment } \\
\hline & $M$ & $\mathrm{SD}$ & $M$ & SD & $M$ & SD \\
\hline Self & $6.4_{a}$ & 0.6 & $5.0_{\mathrm{b}}$ & 1.6 & $3.7_{\mathrm{c}}$ & 1.2 \\
\hline Other & $6.4_{\mathrm{a}}$ & 0.5 & $5.8_{\mathrm{a}}$ & 1.1 & $3.2_{\mathrm{c}}$ & 1.1 \\
\hline
\end{tabular}

Note. Means are on 7-point scales, with higher values indicating higher levels of outcome satisfaction. Means with no subscripts in common differ significantly ( $p<0.05)$, as indicated by a least significant difference test for multiple comparisons between means (Kirk, 1982).

\section{Perceived Satisfaction}

The main dependent variable was perceived satisfaction with outcome. To analyze the data, we first conducted a $2 \times 3$ ANOVA. The ANOVA showed a significant main effect of outcome, $F(2,117)=63.23, p<0.01$, and a significant interaction effect, $F(2,117)=3.24, p<0.05$. To interpret these effects, we performed a least significant difference test for multiple comparisons between means $(p<.05)$. Table II shows the results of this test. As hypothesized, findings revealed that within the overpayment condition, participants judged the other student's satisfaction to be more positive than their own satisfaction. Thus, participants indicated that others are significantly more satisfied with being overpaid than they report themselves to be. As in Experiment 1, there were no effects of the target manipulation within the equal payment and underpayment conditions.

Additionally, it can be noted that we replicated previous equity studies in the self-target condition, which was one of our main goals. In the self-condition, participants were the most satisfied in the equal payment condition, and they were more satisfied in the overpayment condition than in the underpayment condition.

\section{Discussion}

Our main hypothesis- that people think others are more satisfied with being overpaid than they are themselves-was supported. As our results show, people evaluated the other person's satisfaction as greater than their own satisfaction in conditions of overpayment. Thus, as in Experiment 1, these findings suggest a moral superiority effect.

Additionally, within the self-conditions, we found that outcome satisfaction was higher in the equal payment condition than in the overpayment condition, and it was higher in the overpayment condition than in the underpayment condition (see upper row of Table II). This pattern of means is in accordance with previous 
equity findings (e.g., Buunk and Van Yperen, 1989; Van den Bos et al., 1997, 1998). As predicted, this pattern is different within the other-condition: Outcome satisfaction in the equal payment condition and the overpayment condition were equally high (see lower row of Table II). Thus, in Experiment 2, we replicated the moral superiority effect revealed by Experiment 1 . In addition, we replicated the findings of previous equity studies under conditions in which people rated their own satisfaction with the distributed outcomes.

\section{GENERAL DISCUSSION}

The findings of the two experiments reported here are supportive of our line of reasoning. Our findings reveal that people think others are more satisfied with being overpaid than they are themselves. In other words, the present research reveals a moral superiority effect in conditions of overpayment inequity. When people are confronted with a conflict between self-interest and fairness, they think others deal with this conflict differently than they do themselves.

In Experiment 1, participants predicted that the other person would be significantly more satisfied when the other was inequitably advantaged compared to equitably paid. In Experiment 2, this comparison was not statistically significant. This difference in the results across our experiments may have been caused by differences in operationalizations. Importantly, however, in both studies we found that participants expected the other participant's satisfaction with overpayment to be significantly higher than their own satisfaction. Therefore, we have demonstrated a moral superiority effect in a somewhat artificial scenario experiment that allowed clear self-other comparisons to be made (Experiment 2) and in a more realistic ongoing experimental situation (Experiment 1).

Furthermore, in Experiment 2 we replicated the findings of previous equity studies in the conditions where participants rated their own satisfaction. Here participants were the most satisfied when they were equitably paid, and they were more satisfied when they were overpaid relative to underpaid.

In the present paper, we aimed to extend the Messick et al. (1985) findings to judgments that are more commonly measured in equity studies and to reactions to equitable and inequitable arrangements that are more common in everyday life. Furthermore, we wanted to specify the influence of self-interest, as considered by Miller and Ratner (1998). To do this, we have looked at judgments that are twodimensional in nature, in that they are susceptible to both self-interest and fairness motives (i.e., satisfaction ratings; cf. Adams, 1965; Van den Bos et al., 1997). Both Messick et al. (1985) and Miller and Ratner (1998) examined the influence of only one dimension (more vs. less fairness in Messick et al., 1985; more vs. less self-interest in Miller and Ratner, 1998). The conflict between self-interest and fairness makes the difference between one's own and other's reactions particularly intriguing. 
Interestingly, participants' fairness judgments and their satisfaction ratings diverged. In both of our experiments, participants did not think they and others differed in their opinions about outcome fairness. Participants predict the same fairness judgments for themselves as for others: An equitable outcome was judged to be fair, and both advantageous and disadvantageous inequitable arrangements were thought to be unfair. In accordance with other research (e.g., Van den Bos et al., 2004), this suggests that when people are asked to make fairness judgments they are predominantly focused on the fairness component of the judgments they are making. Satisfaction judgments are more susceptible to the conflict between ethicality and self-interest, whereas fairness judgments are mainly focused on the ethical aspect of a reaction (Van den Bos et al., 2004). Researchers may want to explore this implication in future research.

Furthermore, researchers may want to investigate the possibility that a kind of pluralistic ignorance may underlie people's interpretation of others' satisfaction with overpayment. That is, perhaps people underestimate others' abilities to adapt to suboptimal circumstances and see only their own capacities for accepting and living with a somewhat unfair situation.

How do our results relate to self-serving biases? Most people rate themselves above average on a variety of characteristics (see, e.g., Smith and Mackie, 1990), and researchers have repeatedly found that people on average tend to think they are more charitable, cooperative, considerate, kind, loyal, and sincere, among other things, than the typical person but less belligerent, deceitful, gullible, lazy, impolite, and mean (for an overview see Epley and Dunning, 2000). We believe that our moral superiority effect is a self-serving bias in people's reactions to being overpaid. Thus, the results of these experiments suggest that people can show a self-serving bias in reaction to advantageous injustice.

Particularly interesting for the present paper is the article by Epley and Dunning (2000), in which these authors suggest that in social dilemma situations people think they will behave in a better, more moral way than others will do. Clearly, the study of moral superiority in social dilemmas is important. However, social dilemmas of the kind studied by Epley and Dunning (e.g., asking how many flowers one would buy for a good cause or how much money one would donate to charity) do not necessarily invoke fairness motives. In contrast, we studied how people react to unfair distributions and what feelings people have concerning this unfairness. In particular, we focused on the extent to which people think they and others are led by the fairness component or by the self-interest component in the conflict concerning overpayment. Together with the Epley and Dunning (2000) study and the broader literature on self-serving biases (e.g., Smith and Mackie, 1990), our research thus demonstrates the robustness of a moral superiority effect.

A critic might want to ask why we did not find a moral superiority effect in the equity and underpayment inequity conditions, especially in the latter condition. Although we were not completely certain what to expect in these situations, we 
think it would be possible to find a moral superiority effect on satisfaction with underpayment. It may be possible that in our experiments the manipulation was not strong enough, and that in the case of a conflict between self-interest and ethical considerations - as in arrangements of overpayment_- people are more susceptible to self-other differences. When there are two opposing forces, there may be more leeway for self-centered effects (cf., Van Dijk et al., 1999), and hence there is a higher probability for a moral superiority effect. In the equal payment and the underpayment payment conditions, the judgments of people are more uniformly positive or negative, respectively (Adams, 1965). Therefore, it is more difficult for self-centered tendencies to affect people's judgments in these two conditions. Furthermore, Loewenstein et al. (1989) argued that people's attitude towards overpayment can be affected more easily and to a greater extent than people's attitudes towards underpayment. We are thus not saying that moral superiority effects can never be found on satisfaction with equity and underpayment inequity. However, following Adams (1965) and others, we are noting that such effects are less likely to be found because the fairness of these two situations is more obvious to people (fair and unfair, respectively).

But, to return to the main line of reasoning presented here, it seems reasonable to conclude that when there is a conflict between self-interest and fairness, people construe their own and other's reactions differently. Specifically, people show a moral superiority effect in which they believe that others will be more satisfied with advantageous inequity than they will be themselves. We hope that this knowledge, together with other research findings, will contribute to a better understanding of the psychology of the advantaged.

\section{ACKNOWLEDGMENTS}

The work in this paper was supported by grants from the Netherlands Organization for Scientific Research (NWO, 410-21-005-P) and the Social Sciences and Humanities Research Council of Canada.

\section{REFERENCES}

Adams, J. S. (1965). Inequity in social exchange. In Berkowitz, L. (ed.), Advances in Experimental Social Psychology, Vol. 2, Academic Press, New York, pp. 267-299.

Austin, W., McGinn, N. C., and Susmilch, C. (1980). Internal standards revisited: Effects of social comparisons and expectancies on judgments of fairness and satisfaction. J. Exp. Soc. Psychol. 16: $426-441$.

Austin, W., and Walster, E. (1974). Reactions to confirmations and disconfirmations of expectancies of equity and inequity. J. Pers. Soc. Psychol. 30: 208-216.

Beauchamp, T. L. (2001). Philosophical Ethics: An Introduction to Moral Philosophy, 3rd edn., McGraw-Hill, Boston. 
Boles, T. L., and Messick, D. M. (1995). A reverse outcome bias: The influence of multiple reference points on the evaluation of outcomes and decisions. Organ. Behav. Hum. Decis. Process. 61: $262-275$.

Buunk, B. P., and Van Yperen, N. W. (1989). Social comparison, equality, and relationship satisfaction: Gender differences over a ten-year period. Soc. Justice Res. 3: 157180 .

Cates, K. L., and Messick, D. M. (1996). Frequentistic adverbs as measures of egocentric biases. Eur. J. Soc. Psychol. 26: 155-161.

Cohen, R. L. (1986). Justice: Views From the Social Sciences, Plenum, New York.

Epley, N., and Dunning, D. (2000). Feeling "holier than thou": Are self-serving assessments produced by errors in self- or social prediction? J. Pers. Soc. Psychol. 79: 861-875.

Haidt, J. (2000). The moral emotions. In Davidson, R. J., Scherer, K., and Goldsmith, H. H. (eds.), Handbook of Affective Sciences, Oxford: Oxford Press.

Hobbes, T. (1651/1904). Leviathan, or Matter, Forme and Power of a Commonwealth Ecclesiasticall and Civill, Cambridge University Press, Cambridge.

Jencks, C. (1990). Varieties of altruism. In Mansbridge, J. J. (ed.), Beyond Self-Interest, The University of Chicago Press, Chicago.

Kahneman, D., Diener, E., and Schwarz, N. (1999). Well-Being: The Foundations of Hedonic Psychology, Russell Sage Foundation, New York.

Kirk, R. E. (1982). Experimental Design: Procedures for the Behavioral Sciences (2nd ed.), Brooks/Cole, Belmont, CA.

Liebrand, W. B. G., Messick, D. M., and Wolters, F. J. M. (1986). Why are we fairer than others: A cross-cultural replication and extension. J. Exp. Soc. Psychol. 22: 590-604.

Loewenstein, G. F., Thompson, L., and Bazerman, M. H. (1989). Social utility and decision making in interpersonal contexts. J. Pers. Soc. Psychol. 57(3): 426-441.

Messick, D. M. (1993). Equality as a decision heuristic. In Mellers, B. A., and Baron, J. (eds.), Psychological Perspectives on Justice: Theory and Applications, Cambridge University Press, New York, pp. 11-31.

Messick. D. M., Bloom, S., Boldizar, J. P., and Samuelson, C. D. (1985). Why we are fairer than others. J. Exp. Soc. Psychol. 21: 480-500.

Messick, D. M., and Sentis, K. P. (1983). Fairness, preference, and fairness biases. In Messick, D. M. and Cook, K. S. (eds.), Equity Theory: Psychological and Sociological Perspectives, Praeger, New York, pp. 61-94.

Messick, D. M., and Sentis, K. P. (1985). Estimating social and nonsocial utility functions from ordinal data. Eur. J. Soc. Psychol. 15(4): 389-399.

Miller, D. T. (1999). The norm of self-interest. Am. Psychol. 54(12): 1053-1060.

Miller, D. T., and Ratner, R. K. (1998). The disparity between the actual and assumed power of self-interest. J. Pers. Soc. Psychol. 74: 53-62.

Mischel, W., Ebbesen, E. B., and Zeiss, A. M. (1976). Determinants of selective memory about the self. J. Consult. Clin. Psychol. 44: 92-103.

Montada, L. (2002). Doing justice to the justice motive. In Ross, M., and Miller, D. T. (eds.), The Justice Motive in Everyday Life, Cambridge University Press, New York.

Montada, L., Schmitt, M., and Dalbert, C. (1986). Thinking about justice and dealing with one's own privileges. In Bierhoff, H. W. Cohen, R. L., and Greenberg, J. (eds.), Justice in Social Relations. Plenum Press, New York.

Moore, L. M., and Baron, R. M. (1973). Effects of wage inequities on work attitudes and performance. J. Exp. Soc. Psychol. 9: 1-16.

Nisbett, R., and Ross, L. (1980). Human Inference: Strategies and Shortcomings of Social Judgment, Prentice-Hall, Englewood Cliffs, NJ.

Smith, E. R., and Mackie, D. M. (1990). Social Psychology, Worth Publishers, New York.

Van den Bos, K. (1999). What are we talking about when we talk about no-voice procedures? On the psychology of the fair outcome effect. J. Exp. Soc. Psychol. 35: 560577.

Van den Bos, K., Lind, E. A., Vermunt, R., and Wilke, H. A. M. (1997). How do I judge my outcome when I do not know the outcome of others? The psychology of the fair process effect. J. Pers. Soc. Psychol. 72: 1034-1046. 
Van den Bos, K., Peters, S. L., Bobocel, D. R., and Ybema, J. F. (2004). On ethical considerations and egoism-based pleasure: Reactions to advantageous inequity under cognitively busy conditions. Manuscript submitted for publication.

Van den Bos, K., Wilke, H. A. M., Lind E. A., and Vermunt, R. (1998). Evaluating outcomes by means of the fair process effect: Evidence for different processes in fairness and satisfaction judgments. J. Pers. Soc. Psychol. 74: 1493-1503.

Van Dijk, E., Wilke, H., Wilke, M., and Metman, L. (1999). What information do we use in social dilemmas? Environmental uncertainty and the employment of coordination rules. J. Exp. Soc. Psychol. 35: 109-135. 